\title{
DELETERIOUS EFFECTS OF LOSS OF INDEPENDENCE ASSESSED WITH THE KATZ INDEX AFTER AORTIC VALVE REPLACEMENT IN ELDERLY PATIENT
}

\author{
Ngo Thanh Hung ${ }^{1 *}$, Tran Thuy Nguyen ${ }^{1 *}$, Nguyen The Huy ${ }^{l}$, Nguyen Hoang Nam $^{l}$, Camilleri Lionel ${ }^{2}$ \\ ABSTRACT

\section{Introduction} \\ beneficial outcomes after aortic valve \\ replacement.
}

Surgical operative risk of valvular replacement has been widely studied and it has been shown that postoperative complications incidence and mortality increase with patients' age. The aim of this study was to assess among elderly patients whom underwent surgical aortic valve replacement using various scoring system and Geriatric Assessment Indexes to predict postoperative risk and long-term outcome.

Methods and Results: We prospectively evaluated the incidence, over early and late results, of surgical scores and geriatric profile amid 122 intermediate-risk patients, aged 75 years or more who underwent surgical aortic valve replacement. In a univariate analysis, the EuroScore II (OR 1.73, 95\% CI: 1.21-2.48, P =0.002), STS score (OR 1.39, 95\% CI: 1.03-1.88, $\mathrm{P}=0.03$ ) and a Katz index $\leq 5$ (limitation of at least one daily living activity) (OR 3.35, 95\% CI: 1.08-10.35, $\mathrm{P}=0.03$ ) were predictors of a 30-day unfavorable evolution. In a multivariate analysis, only surgical scores were predictive factors. At 6 months, 20 patients had deceased or had to be readmitted to hospital. At 10 years, survival was $48 \%$ [IQR 39-57]. The Katz index $\leq 5$ was the only geriatric test independent of an unfavorable outcome at 6 months (OR 4.51, 95\% CI: $1.25-16.29, \mathrm{P}=0.02)$ and of a deleterious effect over long-term survival (OR 3.00, 95\% CI: 1.58-5.69, $\mathrm{P}=0.001$ ).

Conclusion: In elderly patients, autonomy assessment with the Katz index allows to distinguish a vulnerable population with less
Keywords: Aortic valve, Surgery, Geriatric assessment, Activities of daily living, Risk factors.

\section{INTRODUCTION}

Aortic stenosis is the most frequent valvular pathology, with the prevalence increase among patient above 75 years old. Current treatment of severe, symptomatic aortic stenosis can either be conventional surgical replacement or transcatheter aortic valve implantation (TAVI). Surgical operative risk of valvular replacement has been widely studied and it has been shown that postoperative complications incidence and mortality increase with patients' age (1). Usually, this risk is assessed by the STS score and/or the EuroScore II (2). However, these risk evaluation scores admit some inaccuracies among high-risk patients and especially for older age groups, overestimating (EuroScore) or underestimating (STS score) predicted mortality $(3,4)$. Thereby, they do not take into account patients' geriatric condition, which nevertheless determines their resistance to surgical or interventional stress (5). Geriatric assessment (6) allows, either with isolated test, or combined tests, to classify patients as: "strong", "fragile", "sick or dependent". These tests, combined with surgical

1 Cardiovascular Center, E Hospital, Vietnam

2 C.H.U Gabriel Montpied, 6300 Clermont Fd, France

*Corresponding authors: Nguyen Tran Thuy, Ngo Thanh Hung Email: drtranthuyvd@gmail.com

Address: E Hospital, 87-89 Tran Cung, Hanoi, Vietnam, 10000

Vietnam National University, 114 Xuan Thuy, Hanoi, Vietnam, 10000

Received: 24 May 2021

Accepted: 05 July 2021 
scores, allow adjusting the stress level tolerated by a patient, by orientating the therapeutic strategy as well as to prepare him at best before the intervention. The aim of this work is to assess the geriatric profile's impact on the surgical aortic valve replacement outcomes in patients over 75 years old.

\section{MATERIAL AND METHODS}

This is a single center prospective observational study of a patient cohort, carried out with support from the hospital's Clinical Research fund. Patients' informed consent was obtained prior participating to this data collection.

\section{Patient}

Between January 2002 and January 2006, we included 122 patients aged 75 years or more who isolated aortic valve replacement or associated to tricuspid plasty or myocardial revascularization. Exclusion criteria were: emergency operation, redux and/or endocarditis.

\section{Preoperative assessment}

All patients benefited from a geriatric and cardiology consultation in our institution about four weeks piror to the operation. Anthropometric measurements, cardiovascular risk factors, past cardiovascular events and other comorbidities were collected. Aortic valve diseasecharacteristics, left ventricular function and pulmonary pressures were evaluated with transthoracic echography and catheterization.

Using this prospectively collected data analysis, the operative risk was once again evaluated with the most recent versions of STS Score $(01 / 07 / 2014)$ and EuroScore II (03/10/2011).

Geriatric assessment consisted of four tests: a Mini Mental State Examination (MMSE) for cognitive function (7), a Katz Index evaluating independence in activities of daily living (ADL) (8) and a timed « Get up and Go» test to assess mobility (9).

Follow-Up Assessment: Post-operative data were prospectively collected on patient's hospital discharge and during a consultation when leaving the rehabilitation center. We gathered all in-hospital complications together with those occurring within 30 days. Following definitions were used for

- Perioperative infarction: increased CPKMB above 50, new Q-wave or abnormal ventricular kinetic at echography;

- Low output: inotropes during more than 48 hours, extended ventilator support above 48 hours;

- Renal failure: creatinemia $>200 \mu \mathrm{mol} / \mathrm{L}$ and urea $>20 \mathrm{mmol} / \mathrm{L}$ or dialysis;

- Delirium: above 48h and/or extending hospital stay.

New hospitalizations and mortality at 6 months were prospectively registered during a specific consultation. Long-term mortality data were collected between April and July 2016, by letters to either patients or their families, to their physicians and cardiologists. If there was no reply, a phone investigation and a research into the civil register of the place of birth were carried out.

\section{Statistical Analysis}

Statistical analysis was performed using Stata software (version 13; StataCorp, College Station, Texas, USA). The tests were two-sided, with a type I error set at $\alpha=0.05$. Categorical parameters were expressed as frequencies and associated percentages and continuous data as means \pm standard deviations or as medians with interquartile ranges [IQR], according to statistical distribution (normality verified with ShapiroWilk test). Associations between independent 
groups were analyzed using the Chi-squared test or Fisher's exact test for categorical variables and with Student's t-test or Mann-Whitney's test for quantitative variables (homoscedasticity verified by the F-test of equality of variances). Censored data were estimated using the Kaplan-Meier method and compared using log-rank test and Cox proportional hazard model (for quantitative parameters). Multivariate analyses were performed to take into account possible confounding factors determined according to univariate results and clinical relevance. Results were expressed as odds-ratios (for logistic regression) or hazard-ratios (Cox regression) and 95\% confidence interval.

\section{RESULTS}

Between January 2002 and January 2006, 122 patients with a mean age of $78.9 \pm 2.7$ years (from 75 to 89), underwent geriatric assessment before aortic valve replacement. This procedure was isolated in 79 patients, associated with coronary revascularization in 39 and with tricuspid valve plasty in 4 patients. In all cases, a stented bioprosthesis was implanted. Preoperative patients' characteristics are described in table 1.

Regarding the geriatric evaluation, 24 (19.7\%) patients presented with an impaired cognition (MMSE $\leq 27), 16$ (13.1\%) patients had at least one limitation in ADL $(\mathrm{KATZ} \leq 5)$, and $19(15.6 \%)$ patients had a « Get Up and Go » $\geq$ 20 seconds. Patients with limited ADL or a « Get Up and Go » $\geq 20$ seconds were more often female with a higher EuroScore II.

\section{Postoperative Morbi-mortality}

Cumulative morbi-mortality concerned 53 patients and is reported in tables 2 and 3 . In a univariate analysis, among the various geriatric tests, only the Katz Index and amid the standard predictors, only diabetes, NYHA class IV and high systolic pulmonary artery pressure negatively influenced postoperative outcome. EuroScore II predicted mortality was superimposable to observed mortality, however the STS score moderately underestimated it.

Patients whose postoperative outcome was complicated presented with a higher EuroScore II and STS score than those free from any complication.

In a multivariate analysis, after adjustment with the EuroScore II (Katz $\leq 5$, OR 2.31, 95\% CI: 0.69-7.63, P = 0.17; EuroScore II OR 1.65, 95\% CI: 1.16-2.36, $\mathrm{P}=0,005)$ or the STS mortality score (Katz $\leq 5$, OR 3.08, 95\% CI: 0.97-9.75, P = 0.055; STS score OR 1.37, 95\% CI: $1.01-1.86, \mathrm{P}=0,04)$, the Katz Index lost its prognosis value. Among the standard predictors, only diabetes (OR 3.59, 95\% CI: 1.07-12.06, P = $0.04)$ and coexistent extracardiac arteriopathy (OR 2.89, 95\% CI: 1.03-8.15, P = 0.04) were independent predictors of this event.

\section{Long-term survival}

No patient was lost to follow-up. After a mean follow-up of $8.3 \pm 3.8$ years (max. 13.6 years), 35 patients are alive. At 1, 5 and 10 years, global population survival according to the Kaplan Meier method was respectively $93 \%$ [8696], $79 \%$ [70-85] and $48 \%$ [39-57].

Global survival curves for patients groups with a Katz $\leq 5$ and a Katz $>5$ are reported in Fig. 2 .

None of the patients from the Katz $\leq 5$ group was alive at last follow-up enquiry, whereas the 35 patients alive had no limitation in ADL $(p<0.001)$. In a univariate analysis (table $5)$, patients who had performed a « Get Up and Go » in $\geq 20$ seconds presented with a statistically more significant late death risk. However, cognitive test and EuroScore II had no effect over late survival. Among standard prognosis factors, chronic lung disease and increased systolic 
pulmonary artery pressure were the only ones to negatively influence late survival. In a multivariate analysis after adjustment with surgical risk scores, the Katz Index remained an independent predictor of late mortality. Among the standard prognosis factors, increased pulmonary pressure and aortic cross clamp time were also correlated with this unfavorable outcome (Fig 3).

\section{DISCUSSION}

Among this elderly patient cohort, operated for a surgical aortic valve replacement with intermediate risk, (maintained hemodynamics, no critical situation, low incidence of comorbidity), the loss of independence evaluated with the Katz Index, was an independent predictor of an unfavorable 6-month outcome, and of reduced long-term survival. Therapeutic decision-making in aortic valve disease for elderly patient requires careful evaluation of the intervention-related early risk, in terms of: death, postoperative complications, longer in-hospital stay or recovery as well as life-expectancy on the long-term. For these elderly patients, physiological age often differs from chronological one which explains the heterogeneous clinical evolution further to therapeutic management.

The risks scores, STS and EuroScore, have been developed and updated to assess operative mortality. We notice in this analysis of elderly patients at low risk, that EuroScore II and STS score are significant predictors of morbimortality. On the other hand, in our population surgical scores do not represent any discriminating factor concerning long-term mortality.

These scores take into account multiple preoperative variables related to patient demographic characteristics, comorbidities, severity of the heart disease, hemodynamic impact and complexity of the contemplated surgical procedure. Definition of these variables and their impact in the algorithm vary from one score to another. Therefore, their discriminant role and moreover their calibration in high-risk groups or in elderly patients vary from one score to another (10). The STS underestimates by $40 \%$ predicted mortality "in the top $10 \%$ of predicted risk" (4)". As for the EuroScore, when being a good predictor for patients whose predicted mortality is below $30 \%$, it overestimates this mortality for patients whose predicted mortality is above 30\% (3).

Some of these calibration flaws may result from the small proportion of elderly patients in the population at the base of this model (10). A second limiting element to these surgical scores is their overlooking of more specific elderly patients' variables such as more generally their geriatric profile.

Elderly patients with heart diseases present with a higher incidence of geriatric events than the general population, whether it is frailty, loss of independence, cognitive impairment or depression. These geriatric deficiencies increase the mortality risk or morbid outcome $(5,11-12)$. Geriatric profile strongly impact elderly patient's resistance to stress and consequently determine morbi-mortality after any interventional or surgical procedure $(13,14)$. A high prevalence of frail patients has been observed in an elderly patients' population undergoing percutaneous revascularization, thus negatively impacting longterm outcome (14).

Three different clinical conditions may affect vulnerable elderly patient: frailty, loss of independence (disability) and comorbidity. However, these various conditions seem to be causally related and even some overlapping is observed among these geriatric statuses (15). 
Both frailty and disability impact negatively the outcome of aortic stenosis treatment whether it is conventional surgery (16-17) or TAVI (1819). A global geriatric score combining frailty assessment with clinical and biological data has been evaluated in cardiac surgery. Although rather discriminating in terms of 30 daymortality, its main drawback is a difficult implementation in usual clinical practice as well as not being more efficient than surgical risks scores (17).

Frailty is defined as reduced physiologic reserves and poor regulation of these physiologic systems thus making it difficult to maintain homeostasis with regard to stress. Slowing of gait speed and to a less extent the « timed Get up and Go ", may typify this frailty. Gait speed is increasingly considered as an excellent frailty marker in cardiovascular disease but also as independent factor of poor prognosis (5). Among patients with aortic stenosis, this decreased walking speed is frequently observed, independent of cardiovascular assessments and usual comorbidities and independently associated to a disability (20). In cardiac surgery, a reduced gait speed to cover 5 meters has been identified as a more discriminating predictor than other rating scales to predict morbidity and mortality, incrementing the risk of 2 to 3 (16). Our study did not include a gait test to evaluate frailty but a « timed to Get up and go » which may be less relevant in this population on early outcome.

As for disability, it is characterized by a difficulty or a need for help to perform daily life activities; it is generally evaluated with the Katz Index. Major prognosis impact of this dependence, on the risk of postoperative complications occurrence has been established in a series of patients undergoing non-cardiac thoracic surgery [21]. In cardiac surgery, this autonomy assessment by the Katz Index combined to either some dependence degree while ambulating or to a dementia diagnosis, represents an independent prognosis factor of operative mortality (HR 1.8), and reduced mean-term survival (HR 1.5) (11). For patients whose aortic stenosis is treated by TAVI (22), the Katz Index is an independent and powerful predictor of 30-day mortality (frail $5.5 \%$ vs non frail $1.3 \%, p=0.04$ ) but also of mid-term allcause mortality (HR: 2.67).

Although our study only included low-risk patients over 75 years, free from any critical status, disability assessed by the Katz Index represents an independent powerful predictor of 6-month morbi-mortality and long-term survival decrease. Therefore, these results encourage proposing this test to assess elderly patient's vulnerability whatever his surgical risk level as previous heart surgery or TAVI studies demonstrated $(16,22)$.

\section{Limitations}

The need for a geriatric check-up has determined our study profile requiring excluding patients operated in emergency, redo surgery or endocarditis. It is therefore a much selected population at a rather low-risk. The limited number of patients did probably not allow revealing a discriminating impact to other geriatric tests, but a complete and prospective follow-up of the studied population guarantees the validity of the results.

\section{CONCLUSION}

Surgical aortic valve replacement in elderly patient remains a reliable procedure with low operative mortality and satisfactory long-term survival. Preoperative geriatric assessment appears necessary in clinical practice and allows to define groups with unfavorable outcomes risk and thus to better orientate therapeutic decisionmaking. Among the geriatric tests, the assessment 
of autonomy in ADL in patients presenting with aortic valve disease permits to easily distinguish a group whose results are less satisfactory, therefore allowing better informing them, to propose a specific adapted management, or even choosing a less invasive therapeutic solution.

\section{REFERENCES}

1. Feringa HH, Bax JJ, Karagiannis SE, Noordzij $\mathrm{P}$ et al. Elderly patients undergoing major vascular surgery: risk factors and medication associated with risk reduction. Arch Gerontol Geriat 2009; 48: 116-20.

2. Prins C, de Villiers Jonker I, Botes L, Smit FE.. Cardiac surgery risk-stratification models. Cardiovasc J Afr 2012; 23: 160-4

3. Barili F, Pacini D, Capo A, et al. Does EuroSCORE II perform better than its original versions? A multicenter validation study. Eur Heart J 2013 ;34 :22-9.

4. Dewey TM, Brown D, Ryan, WH, et al. Reliability of risk algorithms in predicting early and late operative outcomes in high-risk patients undergoing aortic valve replacement. J Thoracic Cardiovasc Surg 2008; 135:180-7.

5. Afilalo J, Karunananthan S, Eisenberg $\mathrm{MJ}$, et al. Role of frailty in patients with cardiovascular disease. Am J Cardiol 2009; 103:1616-21.

6. Gallo M. Multiparameter approach to evaluate elderly patients undergoing aortic valve replacement. J Thorac Cardiovasc Surg 2014; 148:1749-51.

7. Shea Gluhm, BA, Jody Goldstein, et all. Cognitive Performance on the Mini-Mental State Examination and the Montreal Cognitive Assessment Across the Healthy Adult Lifespan. Cogn Behav Neurol 2013; 26: 1-5

8. Shelkey M, Wallace M. Katz index of independence in activities of daily living. J Gerontol Nurs 1999; 25: 8-9
9. Ng SS, Hui-Chan CW. The timed up \& go test: its reliability and association with lowerlimb impairments and locomotor capacities in people with chronic stroke. Arch Phys Med Rehabil. 2005 Aug; 86: 1641-7.

10. Rosenhek R, Iung $B$, Tornos $P$, et all. ESC Working group on valvular heat disease position paper: assessing the risk of interventions in patients with valvular heart disease. Eur Heart J 2012;13:822-8.

11. Lee $\mathrm{DH}$, Buth $\mathrm{KJ}$, Martin $\mathrm{Bj}$, et all. Frail patients are at increased risk for mortality and prolonged institutional care after cardiac surgery. Circulation 2010; 121: 973-8.

12. Sanchez E, Vidan MT, Serra JA, et all. Prevalence of geriatric syndromes and impact on clinical and functional outcomes in older patients with acute cardiac diseases. Heart 2011; 97:1602-6.

13. Schoenenberger AW, Stortecky S, Neumann S, et all. Predictors of functional decline in elderly patients undergoing transcatheter aortic valve implantation. European Heart Journal 2013; 34: 684-92.

14. Singh M, Rihal CS, Lennon RJ, et all. Influence of frailty and health status on outcomes in patients with coronary disease undergoing percutaneous revascularization. Circ Cardiovasc Qual Outcomes 2011; 4:496-502.

15. Fried LP, Ferrucci L, Darer J, et al. Untangling the concepts of disability, frailty, and comorbidity: implications for improved targeting and care. J Gerontol Med Sci 2004; 59:255-263.

16. Afilalo J, Eisenberg MJ, Morin JF, et all. Gait speed as an incremental predictor of mortality and major morbidity in elderly patients undergoing cardiac surgery. J Am Coll Cardiol 2010; 56:1668-76.

17. Sûndermann S, Dademasch A, Praetorius J Kempfert J, et all. Comprehensive 
assessment of frailty for elderly high-risk patients undergoing cardiac surgery. Eur J Cardio-thoracic Surg 2011; 39: 33-7.

18. Green P, Woglom AE, Genereux P, et all. The impact of frailty status on survival after transcatheter aortic valve replacement in older adults with severe aortic stenosis. J Am Coll Cardiol Intv 2012; 5:974-81.

19. Sepehri A, Beggs T, et all. The impact of frailty on outcomes after cardiac surgery: a systematic review. J Thorac Cardiovasc Surg 2014; 148:3110-7.

20. Green P, Woglom AE, Genereux P, et all. Gait speed and dependence in activities of daily living in older adults with severe aortic stenosis. Clin Cardiol 2012; 35:307- 14.

21. Fukuse T, Satoda N, Hijiya K, Fujinaga $\mathrm{T}$. Importance of a comprehensive geriatric assessment in prediction of complications following thoracic surgery in elderly patients. Chest. 2005: 127:886-91.

22. Puls M, Sobisiak B, Bleckmann A, et all. Impact of frailty on short- and long-term morbidity and mortality after transcatheter aortic valve implantation: risk assessment by Katz Index of activities of daily living. EuroIntervention 2014; 10:609-19.

Table 1: Baseline Patients' Characteristics and operative data.

\begin{tabular}{|l|c|c|c|}
\hline & $\begin{array}{c}\text { Total } \\
(\mathbf{N = 1 2 2})\end{array}$ & $\begin{array}{c}\text { Katz }>\mathbf{5} \\
(\mathbf{n = 1 0 6})\end{array}$ & $\begin{array}{c}\text { Katz } \leq \mathbf{5} \\
(\mathbf{n = 1 6})\end{array}$ \\
\hline Age, mean \pm SD, years & $78.9 \pm 2.7$ & $78.7 \pm 2.6$ & $79.7 \pm 3.5$ \\
\hline Male sex, n (\%) & $86(70.5)$ & $79(74.5)$ & $7(43.7) *$ \\
\hline Hypertension, n (\%) & $75(61.5)$ & $64(60.4)$ & $11(68.7)$ \\
\hline $\begin{array}{c}\text { Body mass Index, mean } \pm \text { SD, } \\
\text { kg/m }{ }^{2}\end{array}$ & $26.8 \pm 5.9$ & $26.6 \pm 5.3$ & $28.1 \pm 9.0$ \\
\hline Diabetes, n (\%) & $20(16.4)$ & $16(15.1)$ & $4(25.0)$ \\
\hline Smoker, n (\%) & $15(12.3)$ & $13(12.3)$ & $2(12.5)$ \\
\hline Chronic lung disease, n (\%) & $12(9.8)$ & $9(8.5)$ & $3(18.7)$ \\
\hline Extracardiac arteriopathy, n (\%) & $28(22.9)$ & $23(21.7)$ & $5(31.3)$ \\
\hline Neurologic disease & $10(8.2)$ & $9(8.4)$ & $1(6.2)$ \\
\hline Chronic Kidney disease, n (\%) & $3(2.5)$ & $2(1.9)$ & $1(6.2)$ \\
\hline Dyspnea (NYHA), n (\%) & & & \\
\hline I & $10(8.2)$ & $9(8.5)$ & $1(6.2)$ \\
\hline II & $39(31.9)$ & $35(33.0)$ & $4(25.0)$ \\
\hline III & $65(53.3)$ & $56(52.8)$ & $9(56.3)$ \\
\hline IV & $8(6.6)$ & $6(5.7)$ & $2(12.5)$ \\
\hline Prior Myocardial Infarction, n (\%) & $7(5.7)$ & $7(6.6)$ & $0(0.0)$ \\
\hline Heart rate, n (\%) & $19(15.6)$ & $17(16.0)$ & $2(12.5)$ \\
\hline Sinus rhythm & & & $13(81.3)$ \\
\hline Atrial Fibrillation & & & \\
\hline
\end{tabular}




\begin{tabular}{|l|c|c|c|}
\hline \multicolumn{1}{|c|}{ Pace Maker } & $6(4.9)$ & $5(4.7)$ & $1(6.2)$ \\
\hline Hemodynamic & & & \\
\hline PAPs (mmHg), mean $\pm \mathrm{ET}$ & $36.4 \pm 12.8$ & $36.2 \pm 12.9$ & $37.6 \pm 12.3$ \\
\hline LVEF (\%), mean $\pm \mathrm{ET}$ & $66.3 \pm 15.0$ & $66.5 \pm 15.2$ & $64.4 \pm 13.7$ \\
\hline Aortic valve lesion, $\mathrm{n}(\%)$ & & & \\
\hline Stenosis & $93(76.2)$ & $78(73.6)$ & $15(93.8)$ \\
\hline Insufficiency & $2(1.7)$ & $2(1.9)$ & $0(0.0)$ \\
\hline Mixed & $27(22.1)$ & $26(24.5)$ & $1(6.2)$ \\
\hline Coronary lesion, $\mathrm{n}(\%)$ & $49(40.2)$ & $43(40.6)$ & $6(37.5)$ \\
\hline EuroScore II (\%), mean $\pm \mathrm{SD}$ & $2.6 \pm 1.5$ & $2.4 \pm 1.3$ & $3.6 \pm 2.3 * *$ \\
\hline STS Score mortality, median [IQR] & $2.2[1.7-3.1]$ & $2.2[1.7-3.1]$ & $2.5[1.9-3.8]$ \\
\hline Combined Procedure & & & \\
\hline CABG, $\mathrm{n}(\%)$ & $39(32.0)$ & $35(33.0)$ & $4(25.0)$ \\
\hline Tricuspid plasty, $\mathrm{n}(\%)$ & $4(3.3)$ & $3(2.8)$ & $1(6.2)$ \\
\hline Duration (minutes, median [IQR]) & & & \\
\hline Aortic cross clamp time & $76.5[59-96]$ & $77[59-96]$ & $76[66.5-95.5]$ \\
\hline Bypass time & $99[74-120]$ & $99.5[74-120]$ & $99[42.5-117.5]$ \\
\hline Length of stay (days), median [IQR] & & & \\
\hline Intensive care & $4[3-5]$ & $4[3-4]$ & $4[3-5]$ \\
\hline Hospital & $12[11-13]$ & $12[11-13]$ & $12[12-19]$ \\
\hline
\end{tabular}

Table 2: Morbidity and Mortality at 30 days

\begin{tabular}{|l|c|c|c|}
\hline & $\begin{array}{c}\text { Total } \\
(\mathbf{N = 1 2 2})\end{array}$ & $\begin{array}{c}\text { Katz }>\mathbf{5} \\
(\mathbf{n = 1 0 6})\end{array}$ & $\begin{array}{c}\text { Katz } \leq \mathbf{5} \\
(\mathbf{n}=\mathbf{1 6})\end{array}$ \\
\hline Mortality & $3(2.5)$ & $2(1.9)$ & $1(6.2)$ \\
\hline Cardiovascular & & & \\
\hline \multicolumn{1}{|c|}{ Low output } & $11(9.0)$ & $9(8.5)$ & $2(12.5)$ \\
\hline \multicolumn{1}{|c|}{ Perioperative Infarction } & $7(5.7)$ & $7(6.6)$ & $0(0.0)$ \\
\hline \multicolumn{1}{|c|}{ Ventricular arrhythmia } & $3(2.5)$ & $2(1.9)$ & $1(6.2)$ \\
\hline Respiratory failure & $6(4.9)$ & $5(4.7)$ & $1(6.2)$ \\
\hline Renal failure & $14(11.5)$ & $10(9.4)$ & $4(25.0)$ \\
\hline Surgical revision & & & $2(12.5)$ \\
\hline Bleeding & $5(4.1)$ & $3(2.8)$ & $0(0.0)$ \\
\hline Pericardial effusion & $1(0.8)$ & $1(0.9)$ & $1(6.2)$ \\
\hline Sternum & $3(2.5)$ & $2(1.9)$ & \\
\hline
\end{tabular}


Table 3: Morbi-mortality at 30 days. Univariate analysis

\begin{tabular}{|c|c|c|c|c|}
\hline & $\begin{array}{c}\text { Morbi- } \\
\text { Mortality } \\
\text { No }\end{array}$ & $\begin{array}{c}\text { Morbi- } \\
\text { Mortality } \\
\text { Yes }\end{array}$ & OR [IC95\%] & p-value \\
\hline \multicolumn{5}{|l|}{$\mathrm{KATZ} \leq 5, \mathrm{n}(\%)$} \\
\hline No $(n=106)$ & $64(60.4)$ & $42(39.6)$ & REF & REF \\
\hline Yes $(n=16)$ & $5(31.3)$ & $11(68.7)$ & $3.35[1.08 ; 10.35]$ & 0.03 \\
\hline \multicolumn{5}{|l|}{$\mathrm{UP}$ and $\mathrm{GO} \geq 20, \mathrm{n}(\%)$} \\
\hline No $(n=103)$ & $60(58.3)$ & $43(41.7)$ & REF & REF \\
\hline Yes $(\mathrm{n}=19)$ & $9(47.4)$ & $10(52.6)$ & $1.55[0.58 ; 4.14]$ & 0.38 \\
\hline \multicolumn{5}{|l|}{ MMSE $\leq 27, \mathrm{n}(\%)$} \\
\hline No $(n=98)$ & $58(59.2)$ & $40(40.8)$ & REF & REF \\
\hline Yes $(n=24)$ & $11(45.8)$ & $13(54.2)$ & $1.71[0.69 ; 4.21]$ & 0.24 \\
\hline EuroScore II, median [IQR] & $1.9[1.5-2.5]$ & $2.4[2.0-3.5]$ & $1.73[1.21 ; 2.48]$ & 0.002 \\
\hline $\begin{array}{l}\text { Score STS mortality, median } \\
{[\mathrm{IQR}]}\end{array}$ & $2.1[1.6-2.7]$ & $2.6[1.9-3.3]$ & $1.39[1.03 ; 1.88]$ & 0.03 \\
\hline Age, mean \pm SD & $78.6 \pm 2.8$ & $79.1 \pm 2.6$ & $1.07[0.93 ; 1.23]$ & 0.32 \\
\hline Body Mass Index, mean \pm SD & $27.0 \pm 4.8$ & $26.5 \pm 7.1$ & $0.99[0.92 ; 1.05]$ & 0.65 \\
\hline \multicolumn{5}{|l|}{ Diabetes, $\mathrm{n}(\%)$} \\
\hline No $(n=102)$ & $62(60.8)$ & $40(39.2)$ & REF & REF \\
\hline Yes $(n=20)$ & $7(35.0)$ & $13(65.0)$ & $2.88[1.06 ; 7.84]$ & 0.04 \\
\hline \multicolumn{5}{|l|}{ Chronic Lung disease, $\mathrm{n}(\%)$} \\
\hline No $(n=111)$ & $63(56.8)$ & $48(43.2)$ & REF & REF \\
\hline Yes $(n=11)$ & $6(54.5)$ & $5(45.5)$ & $1.09[0.31 ; 3.80]$ & 0.89 \\
\hline \multicolumn{5}{|l|}{$\begin{array}{ll}\text { Extracardiac } & \text { Arteriopathy, } \mathrm{n} \\
(\%) & \end{array}$} \\
\hline No $(n=97)$ & $59(60.8)$ & $38(39.2)$ & REF & REF \\
\hline Yes $(\mathrm{n}=25)$ & $10(40.0)$ & $15(60.0)$ & $2.33[0.94 ; 5.72]$ & 0.06 \\
\hline \multicolumn{5}{|l|}{ Neurologic disease, $\mathrm{n}(\%)$} \\
\hline No $(n=112)$ & $65(58.0)$ & $47(42.0)$ & REF & REF \\
\hline Yes $(n=10)$ & $4(40.0)$ & $6(60.0)$ & $2.07[0.55 ; 7.77]$ & 0.28 \\
\hline \multicolumn{5}{|l|}{ Chronic Kidney disease, n (\%) } \\
\hline No $(n=119)$ & $69(58.0)$ & $50(42.0)$ & NA & NA \\
\hline Yes $(n=3)$ & $0(0.0)$ & $3(100.0)$ & & \\
\hline \multicolumn{5}{|l|}{ Dyspnea (NYHA), n (\%) } \\
\hline $\mathrm{I}(\mathrm{n}=10)$ & $8(80.0)$ & $2(20.0)$ & REF & REF \\
\hline
\end{tabular}




\begin{tabular}{|l|c|c|c|c|}
\hline II $(\mathrm{n}=39)$ & $25(64.1)$ & $14(35.9)$ & $2.24[0.41 ; 12.05]$ & 0.35 \\
\hline III $(\mathrm{n}=65)$ & $34(52.3)$ & $31(47.7)$ & $3.65[0.71 ; 18.51]$ & 0.12 \\
\hline IV $(\mathrm{n}=8)$ & $2(25.0)$ & $6(75.0)$ & $\begin{array}{c}12.00 \\
{[1.29 ; 111.32]}\end{array}$ & 0.03 \\
\hline PAPs, mean \pm SD & $34.3 \pm 10.8$ & $39.0 \pm 14.7$ & $1.03[1.01 ; 1.07]$ & 0.049 \\
\hline LVEF, mean \pm SD & $68.1 \pm 13.7$ & $63.8 \pm 16.3$ & $0.98[0.95 ; 1.01]$ & 0.12 \\
\hline Coronary lesion, $\mathrm{n}(\%)$ & & & & \\
\hline No $(\mathrm{n}=73)$ & $45(61.6)$ & $28(38.4)$ & $\mathrm{REF}$ & REF \\
\hline Yes (n=49) & $24(49.0)$ & $25(51.0)$ & $1.67[0.80 ; 3.49]$ & 0.17 \\
\hline $\begin{array}{l}\text { Aortic cross clamp time } \\
\text { (minutes), median }[\mathrm{IQR}]\end{array}$ & $70[56-89]$ & $80[67-107]$ & $1.01[0.99 ; 1.02]$ & 0.10 \\
\hline
\end{tabular}

PAPs: Systolic Pulmonary artery pressure, LVEF: Left ventricular ejection fraction.

Table 4: Long-term mortality (including in-hospital mortality). Univariate analysis.

\begin{tabular}{|c|c|c|c|c|}
\hline & Survival & Death & HR [IC95\%] & p-value \\
\hline \multicolumn{5}{|l|}{ KATZ $\leq 5, \mathrm{n}(\%)$} \\
\hline No $(n=106)$ & $35(33.0)$ & $71(67.0)$ & REF & REF \\
\hline Yes $(n=16)$ & $0(0.0)$ & $16(100.0)$ & $3.55[2.02 ; 6.21]$ & $<0.001$ \\
\hline \multicolumn{5}{|l|}{$\mathrm{UP}$ and $\mathrm{GO} \geq 20, \mathrm{n}(\%)$} \\
\hline No $(n=103)$ & $32(31.1)$ & $71(68.9)$ & REF & REF \\
\hline Yes $(n=19)$ & $3(15.8)$ & $16(84.2)$ & $1.91[1.10 ; 3.30]$ & 0.02 \\
\hline \multicolumn{5}{|l|}{$\mathrm{MMSE} \leq 27, \mathrm{n}(\%)$} \\
\hline No $(\mathrm{n}=98)$ & $31(31.6)$ & 67 (68.4) & REF & REF \\
\hline Yes $(n=24)$ & $4(16.7)$ & $20(83.3)$ & $1.20[0.73 ; 1.99]$ & 0.46 \\
\hline EuroScore II, median [IQR] & $2.0[1.5-3.1]$ & $2.2[1.7-2.9]$ & $1.14[0.98 ; 1.32]$ & 0.07 \\
\hline Score STS mortality, median[IQR] & $2.1[1.6-2.7]$ & $2.6[1.9-3.3]$ & $1.11[0.95 ; 1.29]$ & 0.17 \\
\hline Age, mean \pm SD & $78.3 \pm 2.2$ & $79.1 \pm 2.9$ & $1.07[0.98 ; 1.16]$ & 0.11 \\
\hline BMI, mean \pm SD & $27.4 \pm 4.5$ & $26.5 \pm 6.4$ & $0.99[0.95 ; 1.04]$ & 0.81 \\
\hline \multicolumn{5}{|l|}{ Diabetes, $\mathrm{n}(\%)$} \\
\hline No $(\mathrm{n}=102)$ & $32(31.4)$ & $70(68.6)$ & REF & REF \\
\hline Yes $(n=20)$ & $3(15.0)$ & $17(85.0)$ & $1.57[0.92 ; 2.67]$ & 0.10 \\
\hline \multicolumn{5}{|l|}{ Chronic Lung disease, $\mathrm{n}(\%)$} \\
\hline No $(\mathrm{n}=111)$ & $34(30.6)$ & $77(69.4)$ & REF & REF \\
\hline Yes $(n=11)$ & $1(9.1)$ & $10(90.9)$ & $2.21[1.14 ; 4.30]$ & 0.02 \\
\hline \multicolumn{5}{|c|}{ Chronic Kidney disease, $\mathrm{n}(\%)$} \\
\hline No $(n=119)$ & $35(29.4)$ & $84(70.6)$ & REF & REF \\
\hline Yes $(n=3)$ & $0(0.0)$ & $3(100.0)$ & $0.55[0.17 ; 1.74]$ & 0.30 \\
\hline
\end{tabular}




\begin{tabular}{|c|c|c|c|c|}
\hline Dyspnea (NYHA), n (\%) & & & & \\
\hline $\mathrm{I}(\mathrm{n}=10)$ & $4(40.0)$ & $6(60.0)$ & REF & REF \\
\hline II $(n=39)$ & $14(35.9)$ & $25(64.1)$ & $0.86[0.35 ; 2.10]$ & 0.74 \\
\hline III $(n=65)$ & $15(23.1)$ & $50(76.9)$ & $1.21[0.51 ; 2.82]$ & 0.66 \\
\hline IV $(n=8)$ & $2(25.0)$ & $6(75.0)$ & $1.56[0.50 ; 4.84]$ & 0.44 \\
\hline PAPs, mean \pm SD & $34.1 \pm 12.2$ & $37.3 \pm 13.0$ & $1.02[1.01 ; 1.04]$ & 0.01 \\
\hline $\mathrm{LVEF}$, mean $\pm \mathrm{SD}$ & $66.5 \pm 15.2$ & $66.2 \pm 15.0$ & $1.00[0.98 ; 1.02]$ & 0.94 \\
\hline \multicolumn{5}{|l|}{ Coronary lesion, n (\%) } \\
\hline No $(n=73)$ & $22(30.1)$ & $51(69.9)$ & REF & REF \\
\hline Yes $(n=49)$ & $13(26.5)$ & $36(73.5)$ & $1.32[0.85 ; 2.03]$ & 0.21 \\
\hline $\begin{array}{l}\text { Aortic cross clamp time } \\
\text { (minutes), median }[\mathrm{IQR}]\end{array}$ & $67[50-80]$ & $80[65-104]$ & $1.00[0.99 ; 1.01]$ & 0.19 \\
\hline
\end{tabular}

PAPs: Systolic Pulmonary artery pressure, LVEF: Left ventricular ejection fraction

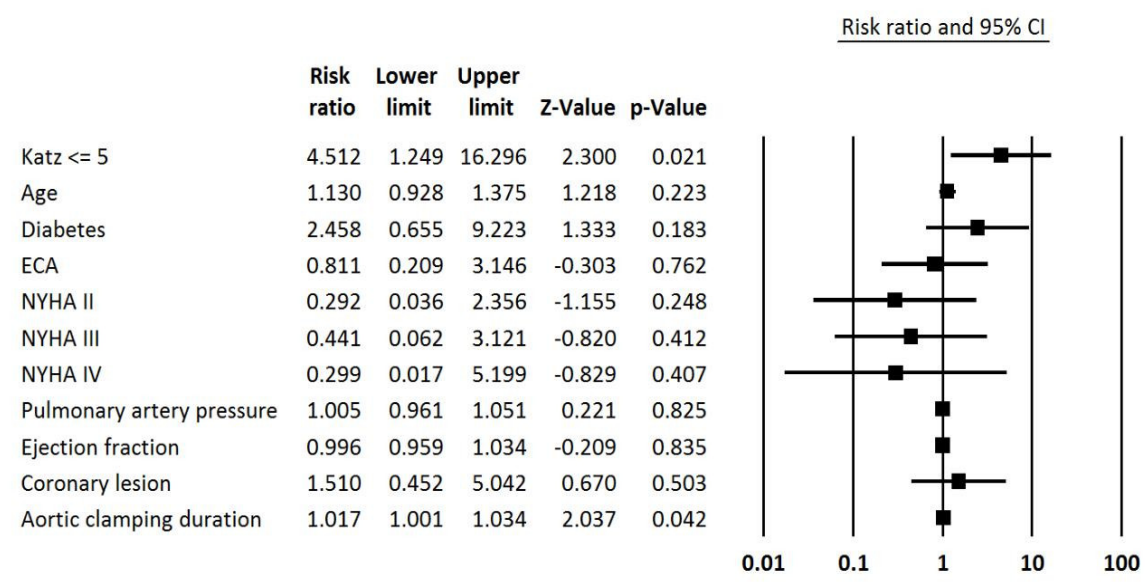

Figure 1:

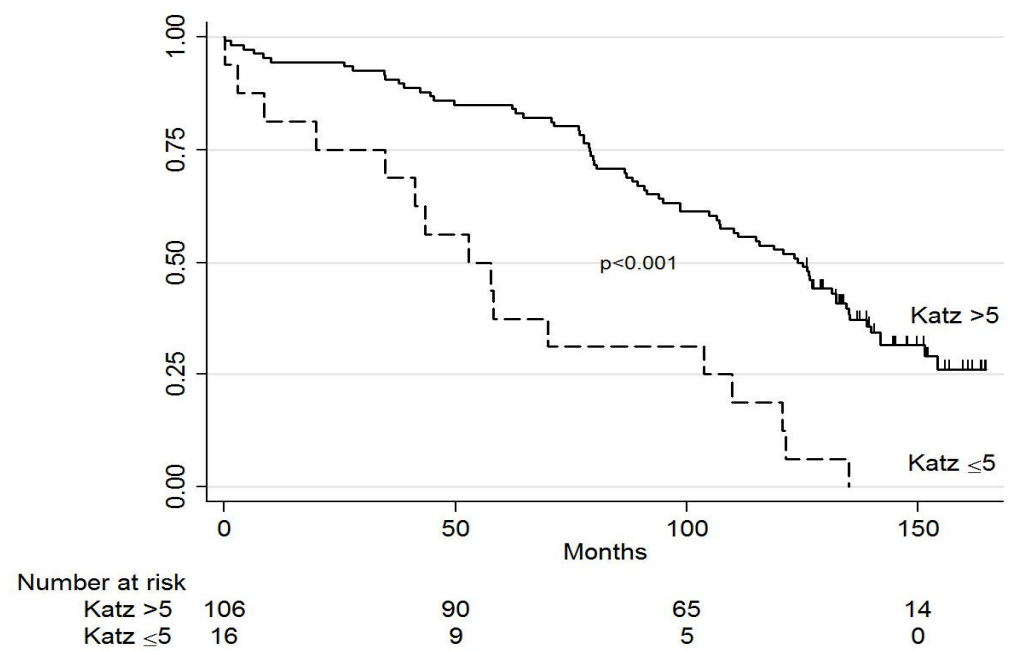

Figure 2: 